\title{
Brief summary of French guidelines for the prevention, diagnosis and treatment of hospital-acquired pneumonia in ICU
}

\author{
Marc Leone ${ }^{1 *}$, Lila Bouadma² , Bélaïd Bouhemad ${ }^{3}$, Olivier Brissaud ${ }^{4}$, Stéphane Dauger ${ }^{5}$, Sébastien Gibot ${ }^{6}$, \\ Sami Hraiech ${ }^{7}$, Boris Jung ${ }^{8}$, Eric Kipnis ${ }^{9}$, Yoann Launey ${ }^{10}$, Charles-Edouard Luyt ${ }^{11}$, Dimitri Margetis ${ }^{12}$, \\ Fabrice Michel ${ }^{13}$, Djamel Mokart ${ }^{14}$, Philippe Montravers ${ }^{15}$, Antoine Monsel ${ }^{16}$, Saad Nseir ${ }^{17}$, Jérôme Pugin ${ }^{18}$, \\ Antoine Roquilly ${ }^{19}$, Lionel Velly ${ }^{20}$, Jean-Ralph Zahar ${ }^{21}$, Rémi Bruyère ${ }^{22}$, Gérald Chanques ${ }^{23}$, ADARPEF and GFRUP
}

\begin{abstract}
Background: The French Society of Anaesthesia and Intensive Care Medicine and the French Society of Intensive Care edited guidelines focused on hospital-acquired pneumonia (HAP) in intensive care unit. The goal of 16 Frenchspeaking experts was to produce a framework enabling an easier decision-making process for intensivists.

Results: The guidelines were related to 3 specific areas related to HAP (prevention, diagnosis and treatment) in 4 identified patient populations (COPD, neutropenia, post-operative and paediatric). The literature analysis and the formulation of the guidelines were conducted according to the Grade of Recommendation Assessment, Development and Evaluation methodology. An extensive literature research over the last 10 years was conducted based on publications indexed in PubMed ${ }^{\mathrm{TM}}$ and Cochrane ${ }^{\mathrm{TM}}$ databases.

Conclusions: HAP should be prevented by a standardised multimodal approach and the use of selective digestive decontamination in units where multidrug-resistant bacteria prevalence was below 20\%. Diagnosis relies on clinical assessment and microbiological findings. Monotherapy, in the absence of risk factors for multidrug-resistant bacteria, non-fermenting Gram-negative bacilli and/or increased mortality (septic shock, organ failure), is strongly recommended. After microbiological documentation, it is recommended to reduce the spectrum and to prefer monotherapy for the antibiotic therapy of HAP, including for non-fermenting Gram-negative bacilli.
\end{abstract}

\section{Introduction}

Hospital-acquired pneumonia (HAP) is the most common infection in the intensive care unit (ICU) [1]. In the ICU, HAP is associated with a mortality rate of $20 \%$ and with increased duration of mechanical ventilation and ICU and hospital length-of-stay [2, 3]. The criteria to diagnose pneumonia are shown in Table 1 (Fig. 1).
*Correspondence: Marc.LEONE@ap-hm.fr

1 Service d'Anesthésie et de Réanimation, Aix-Marseille Universite Hopital Nord, chemin des Bourrely, 13015 Marseille, France

Full list of author information is available at the end of the article

\section{Method}

Sixteen French-speaking experts produce guidelines in three specific areas related to HAP: prevention, diagnosis and treatment as well as the specificities pertaining to different identified patient populations (COPD, neutropenia, post-operative and paediatric). The schedule of the group was defined upstream (Table 2) (Fig. 2).

The questions were formulated according to the PICO (Patient, Intervention, Comparison, Outcome) format. The formulation of the guidelines was conducted according to the GRADE methodology (Grade of Recommendation Assessment, Development and Evaluation) $[4,5]$. In the absence of supporting literature, a question could be addressed by a recommendation under the form of an expert opinion ("the experts suggest that...") (Fig. 3). 


\section{Table 1 Criteria for defining pneumonia}

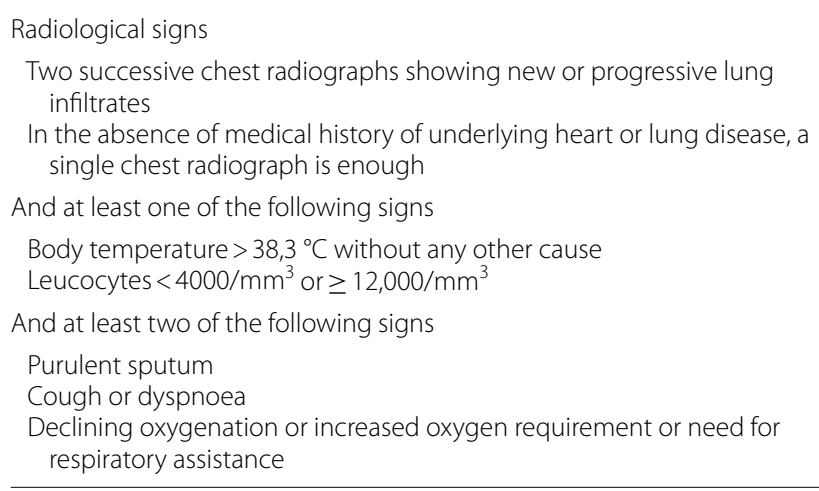

These guidelines with their arguments were published in the journal Anaesthesia Critical Care and Pain Medicine [6] (Fig. 4).

First area, PREVENTION Which HAP prevention approaches decrease morbidity and mortality in ICU patients?

R1.1 We recommend using a standardised multimodal HAP prevention approach in order to decrease ICU patient morbidity (Grade $1+$ ).

R1.1 Paediatrics We suggest using a standardised multimodal approach aiming at preventing HAP in order to decrease paediatric ICU patient morbidity (Grade $2+$ ).

\section{Table 2 Guideline timeline}

\begin{tabular}{ll}
\hline 5 December 2016 & Start-up meeting \\
6 March 2017 & Vote: first round \\
13 March 2017 & Post-vote deliberation meeting \\
1 April 2017 & Vote: second round \\
16 April 2017 & Amendment of two guidelines \\
28 April 2017 & Vote of the two amended guidelines \\
10 May 2017 & Guideline finalisation meeting \\
\hline
\end{tabular}

R1.2 In units where multidrug-resistant bacteria prevalence is low $(<20 \%)$, we suggest applying routine selective digestive decontamination using a topical antiseptic administered enterally and a maximal 5-day course of systemic prophylactic antibiotic to decrease mortality (Grade $2+$ ).

R1.3 Within a standardised multimodal HAP prevention approach, we suggest combining some of the following methods to decrease ICU patient morbidity:

- Promote the use of non-invasive ventilation to avoid tracheal intubation (mainly in post-operative digestive surgery patients and in patients with COPD),

- Favour orotracheal over nasotracheal intubation when required

1- Favour non-invasive ventilation (NIV) (mainly following digestive surgery and for COPD patients)

When invasive ventilation is required :

2- Apply* a selective digestive decontamination protocol with prophylactic systemic antibiotic treatment $<5$ days

*if the prevalence of multiresistant bacteria is low $(<20 \%)$

3- Associate some of the following methods ( $1^{\text {st }}$ line):

Favour the use of NIV to prevent intubation

Limit dose and duration of sedatives and analgesics associated with mechanical ventilation

Initiate early enteral feeding

Regularly verify endotracheal tube cuff pressures

Perform sub-glottic suction (/6-8 hours) using an appropriate endotracheal tube

Favour the orotracheal route for intubation

NB: The association of head of bed elevation $<30^{\circ}$ and/or oro-pharyngeal decontamination with 0.12 or $0.2 \%$ chlorhexidine could be proposed in association to these measures, despite low efficiency, because they do not cost much and are well tolerated.

4- Avoid using the following methods:

Systematic early tracheotomy (apart from specific indications)

Antiulcer prophylaxis (apart from specific indications)

Post-pyloric enteral feeding (apart from specific indications)

Probiotics

Systematic early changing of humidifier filters (apart from a recommendation from the manufacturer)

Closed endo-tracheal suction systems

The use of intubation tubes lined/coated or incorporating silver or antiseptics, or with an "optimised" cuff shape

Oro-pharyngeal decontamination using povidone-iodine

Prophylactic nebulised antibiotics

Daily skin decontamination using antiseptics

Fig. 1 Multimodal healthcare associated pneumonia prevention protocol (expert opinion) 


\section{Protocol 2}

Oro-pharyngeal application ( $x 4 /$ day, until tracheal extubation) of a paste or gel containing

- polymyxin E (2\%)

- tobramycin (2\%)

- amphotericin B (2\%)

Administration ( $x 4 /$ day, until tracheal extubation) through a nasogastric tube of $10 \mathrm{ml}$ of a suspension containing

- 100 mg Polymyxin $\mathrm{E}$

- $80 \mathrm{mg}$ Tobramycin

- 500 mg Amphotericin B

Intravenous administration of a prophylactic antibiotic treatment during 48 to $\mathbf{7 2}$ hours for patients who do not require curative antibiotic therapy

- cefazolin $1 \mathrm{~g} \times 3 / \mathrm{d}^{*}$

- In case of allergy to cephalosporins:

- ofloxacin $200 \mathrm{mg} \times 2 / \mathrm{d}^{*}$

- ciprofloxacin $400 \mathrm{mg} \times 2 / \mathrm{d}^{*}$

(*dosages in the absence of renal failure, provided for information purposes only)

Preparation for selective digestive decontamination (provided for information purposes only)

\begin{tabular}{|l|c|c|}
\hline & Oral gel (jar $125 \mathrm{ml})$ & Suspension (bottles $15 \mathrm{ml})$ \\
\hline polymyxin E & $4 \mathrm{~g}$ & $1 \mathrm{~g}$ \\
\hline gentamicin & $4 \mathrm{~g}$ & $0.8 \mathrm{~g}$ \\
\hline amphotericin B & $4 \mathrm{~g}$ & $5 \mathrm{~g}$ \\
\hline sterile water & $134 \mathrm{ml}$ & $100 \mathrm{ml}$ \\
\hline methylcarboxycellulose & $6 \mathrm{~g}$ & \\
\hline methylparahydroxybenzoate & $0.3 \mathrm{~g}$ & \\
\hline propylene glycol & $50 \mathrm{ml}$ & \\
\hline menthol alcohol & $6 \mathrm{ml}$ & \\
\hline
\end{tabular}

Fig. 2 Selective digestive decontamination protocol (expert opinion) 


\section{Protocol 3}

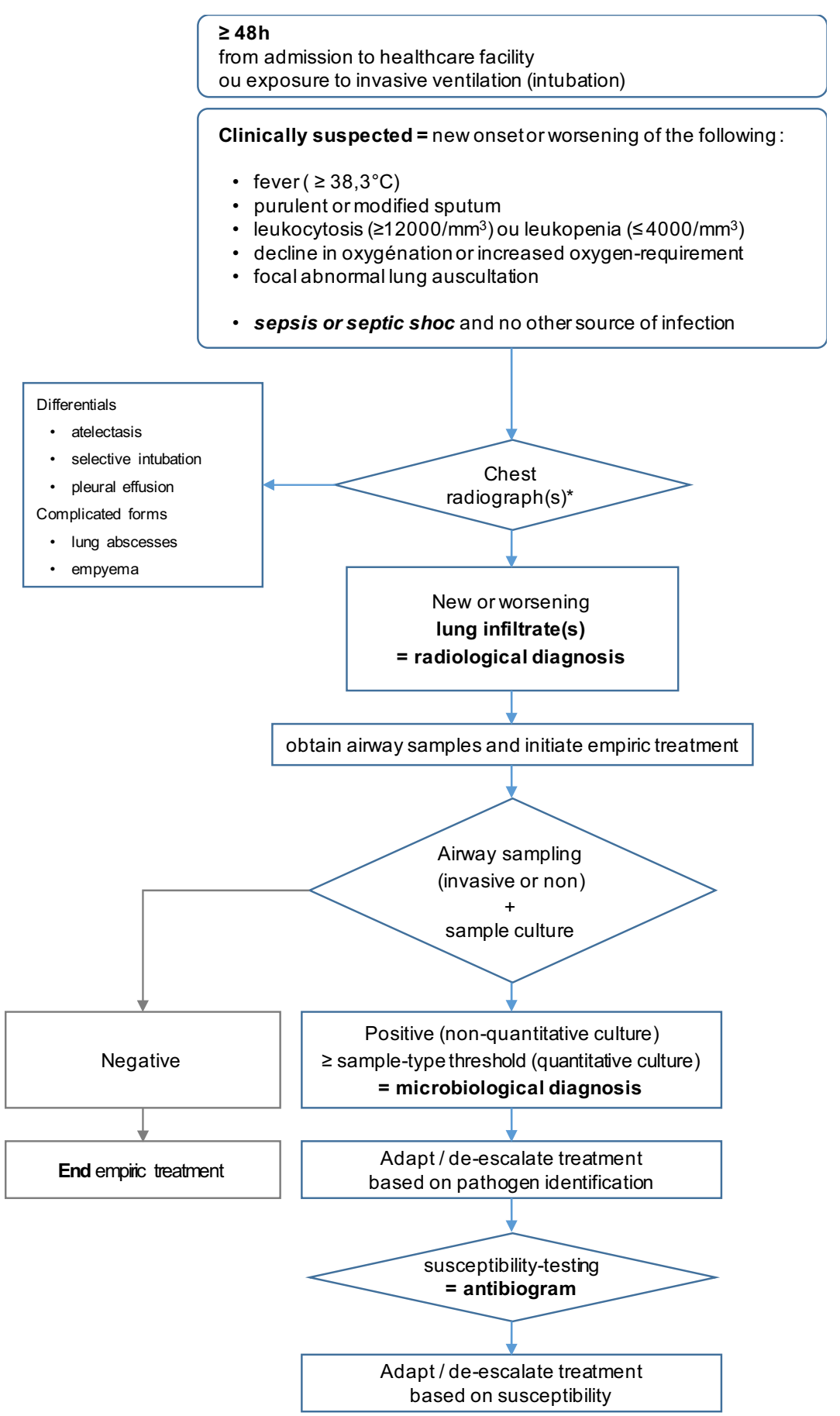

*N.B.: In case of radiographic doubt, it is possible to search for infiltrates using non-contrast thoracic computed tomography or consolidation using ultrasound.

Fig. 3 Diagnostic procedure (expert opinion) 


\section{Protocol 4}

\begin{tabular}{|c|c|c|c|}
\hline Nosological framework & Therapeutic class & Antimicrobials & Dosing regimen $^{\text {a }}$ \\
\hline $\begin{array}{l}\text { Early pneumonia }<5 \text { days } \\
\text { absence of septic shock } \\
\text { absence of MDR bacteria risk } \\
\text { factors }\end{array}$ & $\begin{array}{l}\beta \text {-lactam, } \\
\text { inactive against } P \text {. aeruginosa }\end{array}$ & $\begin{array}{l}\text { amoxicillin/ clavulanic acid } \\
\text { or } \\
3^{\text {rd }} \text { gen. cephalosporin, cefotaxime } \\
\text { In case of allergy to } \beta \text {-lactam : } \\
\text { levofloxacin }\end{array}$ & $\begin{array}{l}3 \text { to } 6 \mathrm{~g} / \mathrm{d} \\
3 \text { to } 6 \mathrm{~g} / \mathrm{d}\end{array}$ \\
\hline $\begin{array}{l}\text { Early pneumonia }<5 \text { days } \\
\text { presence of septic shock } \\
\text { absence of MDR bacteria risk } \\
\text { factors }\end{array}$ & $\begin{array}{l}\beta \text {-lactam, } \\
\text { inactive against } P \text {. aeruginosa }\end{array}$ & $\begin{array}{l}\text { amoxicillin/ clavulanic acid } \\
\text { or } \\
3^{\text {rd }} \text { gen. cephalosporin, cefotaxime } \\
\text { Example: gentamicin } \\
\text { or } \\
\text { Example: ofloxacin } \\
\text { In case of allergy to } \beta \text {-lactam : } \\
\text { Levofloxacin + } \\
\text { Gentamicin }\end{array}$ & $\begin{array}{l}3 \text { to } 6 \mathrm{~g} / \mathrm{d} \\
3 \text { to } 6 \mathrm{~g} / \mathrm{day} \\
8 \mathrm{mg} / \mathrm{kg} / \mathrm{d} \\
200 \mathrm{mg} \times 2 / \mathrm{d} \\
500 \mathrm{mg} \times 2 / \mathrm{d} \\
8 \mathrm{mg} / \mathrm{kg} / \mathrm{d}\end{array}$ \\
\hline $\begin{array}{l}\text { Late pneumonia } \geq 5 \text { days } \\
\quad \text { or } \\
\text { presence of other risk factors for } \\
\text { nonfermenting Gram-negative } \\
\text { bacilli* }\end{array}$ & $\begin{array}{l}\beta \text {-lactam, } \\
\text { ACTIVE against } P \text {. aeruginosa } \\
+ \\
\text { Aminoglycoside }{ }^{b} \\
\text { or } \\
\text { Fluoroquinolone }\end{array}$ & $\begin{array}{l}\text { ceftazidime } \\
\text { or } \\
\text { cefepime } \\
\text { or } \\
\text { piperacillin-tazobactam } \\
\text { or in case of ESBL }{ }^{c} \\
\text { Imipenem-cilastatine } \\
\text { or } \\
\text { meropenem } \\
+ \\
\text { amikacin }{ }^{\text {d }} \\
\text { or } \\
\text { ciprofloxacin } \\
\text { In case of allergy to } \beta \text {-lactam } \\
\text { aztreonam } \\
+ \\
\text { clindamycin }\end{array}$ & $\begin{array}{l}6 \mathrm{~g} / \mathrm{d} \\
4 \text { to } 6 \mathrm{~g} / \mathrm{d} \\
16 \mathrm{~g} / \mathrm{d} \\
3 \mathrm{~g} / \mathrm{d} \\
3 \text { to } 6 \mathrm{~g} / \mathrm{d} \\
30 \mathrm{mg} / \mathrm{kg} / \mathrm{d} \\
400 \mathrm{mg} \times 3 / \mathrm{d}\end{array}$ \\
\hline $\begin{array}{l}\text { Any presentation, } \\
\text { presence of MRSA risk factors** }\end{array}$ & $\begin{array}{l}\text { add agent active against } \\
\text { MRSA }\end{array}$ & $\begin{array}{l}\text { vancomycin } \\
\text { or } \\
\text { linezolid }\end{array}$ & $\begin{array}{l}15 \mathrm{mg} / \mathrm{kg} \text { loading followed by } \\
30 \text { to } 40 \mathrm{mg} / \mathrm{kg} / \mathrm{d} \text { continuous } \\
600 \mathrm{mg} \times 2 / \mathrm{d}\end{array}$ \\
\hline
\end{tabular}

a Doses are given for information purposes only in patients with normal renal function and standard weight; ${ }^{b}$ Favour the use of aminoglycosides over fluoroquinolones to limit emergence of MDR bacteria; ${ }^{c}$ According to the guidelines' criteria " Reduce de use of antibiotics in intensive care unit» ; ${ }^{d}$ Favour the use of amikacin over gentamicin due to enhanced efficacy against non-fermenting Gram-negative bacilli.

*Risk factors for non-fermenting Gram-negative bacilli: antibiotic therapy in the previous 90 days, prior hospital stay of more than 5 days, renal replacement therapy requirement during pneumonia, septic shock, acute respiratory distress syndrome.

** Methicillin-resistant Staphylococcus aureus (MRSA) risk factors: high local prevalence of MRSA, recent colonisation by MRSA, chronic skin lesions, chronic renal replacement therapy.

Fig. 4 Treatment options (expert opinion) 
- Limit dose and duration of sedatives and analgesics (promote their use guided by sedation/pain/ agitation scales, and/or daily interruptions),

- Initiate early enteral feeding (within the first $48 \mathrm{~h}$ of ICU admission),

- Regularly verify endotracheal tube cuff pressure,

- Perform sub-glottic suction (every 6 to $8 \mathrm{~h}$ ) using an appropriate endotracheal tube (Grade 2+).

R1.4 Within a standardised multimodal HAP prevention approach, we suggest not using the following methods to decrease ICU patient morbidity:

- Systematic early (<day 7 ) tracheotomy (except for specific indications),

- Anti-ulcer prophylaxis (except for specific indications),

- Post-pyloric enteral feeding (except for specific indications),

- Administration of probiotics and/or synbiotics,

- Early systematic change of the humidifier filter (except for specific manufacturer recommendations)

- Use of closed suctioning systems for endotracheal secretions,

- Use of antiseptic-coated intubation tubes or with tubes an "optimised" cuff shape,

- Selective oropharyngeal decontamination (SOD) with povidone-iodine,

- Use of prophylactic nebulised antibiotics,

- Daily skin decontamination using antiseptics (Grade 2-).

R1.5 In weaning of COPD patients from ventilation, we suggest using non-invasive ventilation to reduce length of invasive mechanical ventilation, incidence of HAP, morbidity and mortality (Grade 2+).

Second area, DIAGNOSIS What methods to diagnose HAP should be used to decrease ICU patient morbidity and mortality?

R2.1 We suggest not using the clinical scores (CPIS, modified CPIS) for diagnosing HAP (Grade 2-).

R2.2 We suggest collecting microbiological airway samples, regardless of type, before initiation of any change in antibiotic therapy (Grade $2+$ ).

R2.2 Paediatrics We suggest collecting microbiological airway samples, regardless of type, before initiation of any change in antibiotic therapy (Grade $2+$ ).
R2.3 We suggest not measuring plasma or alveolar levels of procalcitonin or soluble TREM-1 to diagnose HAP (Grade 2-).

Third area, TREATMENT What therapeutic options for HAP should be used to decrease ICU patient morbidity and mortality?

R3.1 We suggest immediately collecting samples and initiating antibiotic treatment taking into consideration risk factors for multidrug-resistant bacteria in patients with suspected HAP and haemodynamic or respiratory compromise (shock or acute respiratory distress syndrome) or frailty such as immunosuppression [95-100] (Grade 2+).

R3.2 We recommend treating HAP in mechanically ventilated immunocompetent patients empirically by a monotherapy, in the absence of risk factors for multidrug-resistant bacteria, non-fermenting Gram-negative bacilli and/or increased mortality (septic shock, organ failure) [101-113] (Grade 1+).

R3.3 The experts suggest not systematically directing empiric antibiotic therapy against methicillinresistant Staphylococcus aureus in the treatment of HAP [114-119] (Experts Opinion).

R3.4 We suggest reducing the spectrum and preferring monotherapy for the antibiotic therapy of HAP after microbiological documentation, including for non-fermenting Gram-negative bacilli [114,115, 120-128] (Grade 2+).

R3.5 We recommend not prolonging for more than 7 days the antibiotic treatment for HAP, including for non-fermenting Gram-negative bacilli, apart from specific situations (immunosuppression, empyema, necrotising or abscessed pneumonia) [129-135] (Grade 1-).

R3.6 We suggest administering nebulised colimycine (sodium colistiméthate) and/or aminoglycosides in documented HAP due multidrug-resistant Gram-negative bacilli documented pneumonia established as sensitive to colimycin and/or aminoglycoside, when no other antibiotics can be used (based on the results of susceptibility testing) [136-152] (Grade 2+).

R3.7 We recommend not administering statins as adjuvant treatment for HAP [153-161] (Grade $1-)$.

\section{Authors' contributions}

Marc Leone and Lila Bouadma proposed the elaboration of this recommendation and manuscript in agreement with the "Société Française d'Anesthésie et de Réanimation" and the "Société de Réanimation de Langue Française"; 
Gérald Chanques, Rémi Bruyère and Lionel Velly wrote the methodology section and gave the final version with the final presentation. Antoine Roquilly, Charles-Edouard Luyt and Jean-Ralph Zahar contributed to elaborate recommendations and write the rationale of question 1 (prevention). Sébastien Gibot, Bélaïd Bouhemad, Jérome Pugin and Eric Kipnis contributed to elaborate recommendations and to write the rationale of question 2 (diagnosis). Antoine Monsel, Sami Hraiech and Boris Jung contributed to elaborate recommendations and to write the rationale of question 3 (treatment). Djamel Mokart contributed to elaborate recommendations and to write the rationale about neutropenic patients. Saad Nseir contributed to elaborate recommendations and to write the rationale about COPD patients. Olivier Brissaud, Stéphane Dauger and Fabrice Michel contributed to elaborate paediatrics recommendations and to write the rationale of paediatrics issues. Antoine Launey and Dimitri Margetis provide references. Marc Leone and Lila Bouadma drafted the manuscript. All authors read and approved the final manuscript.

\section{Author details}

${ }^{1}$ Service d'Anesthésie et de Réanimation, Aix-Marseille Universite Hopital Nord, chemin des Bourrely, 13015 Marseille, France. ${ }^{2}$ Service de Réanimation Médicale, Hopital Bichat - Claude-Bernard, AP-HP, Paris, France. ${ }^{3}$ Service d'Anesthésie et Réanimation, Centre Hospitalier Universitaire de Dijon, Paris, France. ${ }^{4}$ Unité de Réanimation Pédiatrique, Hôpital Pellegrin, Centre Hospitalier Universitaire de Bordeaux, Bordeaux, France. ${ }^{5}$ Service de Réanimation Pédiatrique, Hopital Universitaire Robert-Debre, Paris, France. ${ }^{6}$ Service de Réanimation Médicale, CHU de Nancy, Vandoeuvre-les-Nancy, France. ${ }^{7}$ Service de Réanimation des Détresses Respiratoires et des Infections Sévères, AixMarseille Universite, Hopital Nord, Marseille, France. ${ }^{8}$ Service d'Anesthésie et Réanimation, CHU de Montpellier, Montpellier, France. ${ }^{9}$ Service d'Anesthésie et Réanimation, CHU de Lille, Lille, France. ${ }^{10}$ Service d'Anesthésie et Réanimation, Centre Hospitalier Universitaire de Rennes, Rennes, France. ${ }^{11}$ Institut de Cardiologie, Service de Réanimation Médicale, Hopital Universitaire Pitie Salpetriere, AP-HP, Paris, France. ${ }^{12}$ Service de Réanimation Médicale - Hôpital Saint-Antoine, Paris, France. ${ }^{13}$ Service d'Anesthésie et Réanimation, Hopital La timone, Assistance Publique Hopitaux de Marseille, Marseille, France. ${ }^{14}$ Service de Réanimation, Institut Paoli-Calmettes, Marseille, France. ${ }^{15}$ Département d'Anesthésie Réanimation, CHU Bichat - Claude-Bernard, AP-HP, Paris, France. ${ }^{16}$ Département d'Anesthésie et Réanimation, Université Pierre et Marie Curie, Paris, France. ${ }^{17}$ Centre de Soins Intensifs, Service de Réanimation, Centre Hospitalier Regional Universitaire de Lille, Lille, France. ${ }^{18}$ Service de Soins Intensifs, Hopitaux Universitaires de Geneve, Geneve, Switzerland. ${ }^{19}$ Service d'Anesthésie et Réanimation, CHU de Nantes, Nantes, France. ${ }^{20}$ Département d'Anesthésie et Réanimation, Hopital de la Timone, AP-HM, Paris, France. ${ }^{21}$ Département de Microbiologie Clinique, Hopital Avicenne, APHP, Paris, France. ${ }^{22}$ Service de Réanimation, Centre Hospitalier de Bourg-en-Bresse, Bourg-en-Bresse, France. ${ }^{23}$ Département d'Anesthésie Réanimation, Centre Hospitalier Regional Universitaire de Montpellier, Montpellier, France.

\section{Acknowledgements}

Guidelines reviewed and endorsed by the SFAR (29/06/2017) and SRLFboards (08/06/2017).

\section{Competing interests}

The authors declare the following competing interests: Sébastien Gibot: Inotrem S.A, Eric Kipnis: Astellas; LFB; Pfizer, Marc Leone: MSD; Basilea, CharlesEdouard Luyt: Bayer Healthcare; Thermo Fisher BRAHMS; MSD; Biomerieux, Djamel Mokart: Gilead; Basilea; MSD, Philippe Montravers: Pfizer; MSD; Basilea; AstraZeneca; Bayer; Menari; Parexel; Cubist, Saad Nseir: Medtronic; Cielmedical; Bayer, Jérôme Pugin: Bayer; part of the scientific committee for the Amikacin
Inhale study, Jean-Ralph Zahar: MSD; Bard. The remaining authors declare no competing interests.

\section{Availability of data and materials}

Not applicable.

\section{Consent for publication}

Not applicable.

Ethics approval and consent to participate

Not applicable.

\section{Funding}

This work was financially supported by the Société Française d'Anesthésie et de Réanimation (SFAR) and the Société de Réanimation de Langue Française (SRLF).

\section{Publisher's Note}

Springer Nature remains neutral with regard to jurisdictional claims in published maps and institutional affiliations.

Received: 11 August 2018 Accepted: 8 October 2018

Published online: 03 November 2018

\section{References}

1. Koulenti D, Tsigou E, Rello J. Nosocomial pneumonia in 27 ICUs in Europe: perspectives from the EU-VAP/CAP study. Eur I Clin Microbiol Infect Dis. 2016;36:1999.

2. Giuliano KK, Baker D, Quinn B. The epidemiology of nonventilator hospital-acquired pneumonia in the United States. Am J Infect Control. 2017:46:322.

3. Melsen WG, Rovers MM, Groenwold RH, Bergmans DC, Camus C, Bauer TT, Hanisch EW, Klarin B, Koeman M, Krueger WA, Lacherade JC, Lorente L, Memish ZA, Morrow LE, Nardi G, van Nieuwenhoven CA, O'Keefe GE, Nakos G, Scannapieco FA, Seguin P, Staudinger T, Topeli A, Ferrer M, Bonten MJ. Attributable mortality of ventilator-associated pneumonia: a meta-analysis of individual patient data from randomised prevention studies. Lancet Infect Dis. 2013;13(8):665-71.

4. Atkins D, Best D, Briss PA, Eccles M, Falck-Ytter Y, Flottorp S, et al. Grading quality of evidence and strength of recommendations. BMJ. 2004;328(7454):1490.

5. Guyatt GH, Oxman AD, Vist GE, Kunz R, Falck-Ytter Y, Alonso-Coello P, et al. GRADE: an emerging consensus on rating quality of evidence and strength of recommendations. BMJ. 2008;336(7650):924-6.

6. Leone M, Bouadma L, Bouhemad B, Brissaud O, Dauger S, Gibot S, Hraiech S, Jung B, Kipnis E, Launey Y, Luyt CE, Margetis D, Michel F, Mokart D, Montravers P, Monsel A, Nseir S, Pugin J, Roquilly A, Velly L, Zahar JR, Bruyère R, Chanques G. Hospital-acquired pneumonia in ICU. Anaesth Crit Care Pain Med. 2018;37(1):83-98.

\section{Submit your manuscript to a SpringerOpen ${ }^{\odot}$ journal and benefit from:}

- Convenient online submission

- Rigorous peer review

- Open access: articles freely available online

- High visibility within the field

- Retaining the copyright to your article

Submit your next manuscript at $\boldsymbol{\nabla}$ springeropen.com 